\title{
Courage, luck and patience: in celebration of the 80th birthday of Georg W. Kreutzberg
}

\author{
Manuel B. Graeber • Richard B. Banati • \\ Alexander Flügel $\cdot$ Wolfgang J. Streit • \\ Wolfram Tetzlaff
}

Received: 3 August 2012/Accepted: 4 August 2012/Published online: 12 August 2012

(C) Springer-Verlag 2012

We need courage, luck and patience (in German, Wir brauchen: Mut, Glück und Geduld) was the research motto of the Kreutzberg Lab and this was not an abstract statement. As our celebratory article aims to illustrate, the three beliefs encapsulated in this motto were of special significance during different phases of Professor Georg W. Kreutzberg scientific career, or "GWK" as co-workers and close colleagues also refer to him. The respective time periods encompass three key birthdays: 30,50 and 80 .

\footnotetext{
M. B. Graeber $(\bowtie)$

Brain Tumour Research Laboratories, The Brain and Mind Research Institute, University of Sydney, 94 Mallett Street, Camperdown, NSW 2050, Australia

e-mail: manuel@graeber.net

\section{R. B. Banati}

Life Sciences Division, Australian Nuclear Science and Technology Organisation (ANSTO), Integrated Biology, Locked Bag 2001, Kirrawee DC, NSW 2232, Australia

\section{R. B. Banati}

National Imaging Facility and Ramaciotti Centre for Brain Imaging, The Brain and Mind Research Institute, University of Sydney, 100 Mallett Street,

Camperdown, NSW 2050, Australia
}

\section{A. Flügel}

Department of Neuroimmunology, Institute for Multiple Sclerosis Research, University of Göttingen, Waldweg 33, 37073 Göttingen, Germany

\section{W. J. Streit}

Department of Neuroscience, University of Florida College of Medicine, Gainesville, FL 32610-0244, USA

\section{W. Tetzlaff}

Blusson Spinal Cord Centre and University of British Columbia, 818 West 10th Avenue, Vancouver, BC V5Z 1M9, Canada
GWK would sometimes mention his research motto when a suitable occasion arose, typically to pick out a point made during a scientific discussion. On one occasion, he also wrote it onto a laboratory door using white chalk. Black board-like was the finish of the doors in his Department of Neuromorphology at the Max-Planck-Institute of Neurobiology in Martinsried near Munich. The Department had been relocated in 1984 together with the Theoretical Institute of the Max-Planck-Institute of Psychiatry; the latter was renamed MPI of Neurobiology in 1998. GWK's Department was in the direct tradition of Walther Spielmeyer's (1879-1935) who had succeeded both Alois Alzheimer (1864-1915) (as laboratory head) and Emil Kraepelin (1856-1926) (as institute director). Spielmeyer trained 180 neuropathologists from 25 countries [9, 14]. Examples include Harry M. Zimmerman (1901-1995) who won Albert Einstein's name for Yeshiva University's Albert Einstein College of Medicine [9] and Hans Gerhard Creutzfeldt (1885-1964) who is remembered with Alfons Maria Jakob (1884-1931) for the now famous disease named after them. Spielmeyer's successors were Willibald Scholz (1889-1971) and Gerd Peters (1906-1987), respectively, who wrote the first and most important German textbook of neuropathology [13]. Georg Kreutzberg took over the role of neuropathologist and head of the institute in 1984 for a period of 11 years during which the MPI of Psychiatry in Martinsried became ranked third in the world of neuroscience by Thomson Reuters. With Georg Kreutzberg's retirement and the associated closure of his Department in 2000, the tradition of the famous Munich school of neuropathology ended in Germany.

GWK's handwritten motto stayed on that door, which belonged to "Diddi's" (Dietmute Büringer) and "Irmi's" (Irmtraud Milojević) electron microscopy (EM) laboratory, for a long time. It fit well with this environment because the EM laboratory was close to the heart of Georg 
Kreutzberg as well as his own research interest. We shall see later how crucial EM was for a discovery that only now, almost half a century later, is beginning to be fully appreciated. Many of the highly cited papers (see below) that have come out of Georg Kreutzberg's Department have an EM component.

The fact that GWK's motto was not wiped off for years only deepened the impression it left. Computers had already begun to replace handwriting. Of course, the possibility exists that GWK's Department simply had bad cleaners but looking at all the evidence now after GWK's research programme has been successfully completed, the alternative hypothesis that the Max-Planck-Society hires smart cleaners is far more difficult to reject.

\section{Early biography}

Georg Wilhelm Kreutzberg was born in Ahrweiler, Germany, on 2 September 1932. From 1939 to 1942, he attended the Elementary School and from 1942 to 1951, the Gymnasium (State High School) in Ahrweiler. Bad NeuenahrAhrweiler is a small town in Rhineland-Palatinate, a German federal state, and the place where GWK's ancestor, the vintner Georg Kreuzberg discovered a fountain that produces naturally carbonated water. In 1852, he named it after Saint Apollinaris of Ravenna, a locally revered saint. Apollinaris water is now enjoyed in more than 40 countries. Due to frequent excursions to the nearby Rhine valley, young Georg developed an interest in Rhine stones and minerals that could be found there which gave rise to his early interest in chemistry, but he also used a microscope, which he shared with his one and a half-year older brother. The secondary school Georg Kreutzberg attended, the Ahrweiler Gymnasium, left a long-lasting impression on him because it bolstered a rich academic atmosphere. Quite exceptional at the time and also for German schools today, the majority of its teachers held a doctorate and some were still engaged in academic activities while teaching at the school. Following his Abitur (final high school exam) in 1951, GWK pursued his medical studies in Bonn and Freiburg im Breisgau (Germany) but also gave in to "Wanderlust" that led him to study at the universities of Innsbruck and Vienna (Austria). In addition, he engaged in biochemical studies at the University of Bonn during his semester vacations. GWK passed the State Examination in Medicine at the University of Freiburg in 1957. According to the medical doctor-training scheme at the time, this examination was followed by internships, which GWK spent at clinics of the Universities of Bonn and Freiburg (1957-1959). In 1960, he obtained his general medical license.

In 1961, the University of Freiburg awarded the Dr. med. degree to GWK for a thesis entitled, "Studies on the metabolism of tryptophan in various diseases of the nervous system" which he had undertaken in their Psychiatry Department. GWK had a long-standing interest in chemistry and developed a special interest in physiological chemistry (biochemistry) which was relatively new at the time, and according to his own words, he was considered sort of a "mooncalf" by his peers because he pursued neurochemistry in a Psychiatry Department that was very much influenced by the philosophy of Martin Heidegger and whose patient records would even reflect his literary style. Heidegger still filled large lecture halls at the University of Freiburg, and GWK attended Heidegger's lectures with great interest. However, GWK's fascination by the biological basis of brain diseases predominated and took him to Bonn where the first Chair of Neuropathology in Germany had been created for Professor Gerd Peters. Thus, starting in 1960, Georg Kreutzberg received 5 years of training in basic neuropathology under Gerd Peters, first at the Brain Research Institute and Department of Neuropathology at the University of Bonn (1960) and then as research assistant in neuropathology (1961-1964) at the Max-Planck-Institute of Psychiatry (Deutsche Forschungsanstalt für Psychiatrie) in Munich where he had moved together with Peters.

\section{A central question}

In 1963, GWK published his first major research paper as a single author in Nature. Its topic, the axonal reaction of the nerve cell [10], should remain central to his entire research career inspiring experiments that led to discoveries which grew into important new research themes such as retrograde axonal flow, dendritic transport, perineuronal glia, microglia in particular and of course "synaptic stripping". These research topics are all closely related to the same fundamental and ultimately clinical problem, i.e. what a nerve cell does if its main process is injured. Very few if any other research programmes can be named that have had a greater impact on the development of experimental neuropathology as a discipline [11].

A postdoctoral fellowship followed (1964-1965) in the newly established Department of Psychology at the Massachusetts Institute of Technology (MIT) in Cambridge, MA, USA, which was being set up by Hans-Lukas Teuber (1916-1977), a pre-World War II German emigrant. The great professionalism of "Luk" Teuber's operation, which featured regular departmental conferences that were attended by scientists such as David Hubel and Torsten Wiesel, was most inspiring for GWK. The scientific purpose of his stay was to learn autoradiography on nervous tissue and life-long friendships with Joe Altman and Walle Nauta ensued. The techniques learned proved crucial for GWK's later description of dendritic transport and 
axotomy-induced microglial proliferation. GWK returned from MIT to the Max-Planck-Institute of Psychiatry in Munich as a research associate (1965-1967) before serving as Guest Investigator at Rockefeller University in New York by invitation of Paul Weiss (1968), the discoverer of axonal transport. A key publication on blockage of intraaxonal enzyme transport by colchicine soon followed [12].

\section{The Department}

After GWK's second stay in the USA, a most attractive environment for scientists from Germany at the time, which only twenty some years after the war did not enjoy comparable working conditions, Georg Kreutzberg was appointed Chief of Section for Experimental Neuropathology at the Max-Planck-Institute of Psychiatry, Munich, in 1969. In 1971, he obtained the Degree of Dozent in "General and Experimental Neuropathology" at the Medical School of the Technical University of Munich and was promoted to the rank of external (apl.) Professor at the same university in 1977 without the obligation to carry out clinical work. Indeed, it was experimental neuropathology Georg Kreutzberg represented like nobody else. However, coming from a medical background, it certainly took courage at the time to choose a career without the financial safety of clinical work and to compete with the best basic scientists in a "Max Planck environment". Job security finally arrived with the appointment as a Scientific Member of the Max-Planck-Institute of Psychiatry, Munich, in 1978.

The authors of this article remember the site visits conducted by the MPI's international advisory board. The composition of such boards changes according to international scientific developments and institutional fashions over time. It seems quite courageous in retrospect that GWK withstood pressure from less benevolent referees who, belonging to a more reductionist school of thought and who seemed quite adherent to what one might call single hypothesis-driven (and sometimes mislead) research, did not understand the importance of a "systems"-based approach of which GWK's facial nerve axotomy paradigm was representative. Of course, this has changed completely with the arrival of systems biology as a widely accepted concept during the last decade, but at the time, work on pathologically altered and thus even more complex tissue conditions clearly was not to the liking of such reviewers of our work. Such individuals usually favoured a cell culture-based approach. Focusing on testing nature the way they thought things should work rather than giving chance a chance (importance of serendipity) and careful planning to allow true discoveries to be made was another difference in thinking. Clearly, the fundamentally new insights into microglial biology that were obtained in
GWK's department would not have been possible had such voices not been boldly ignored.

\section{Laboratory sociology}

Generations of research and doctoral students, post-docs and senior visiting scientists received friendly and helpful advice along with a dose of "Stallgeruch" ("smell of the stable") not only from GWK but also from his associates notably Dr. Martin Reddington, who became his right hand managing the Department when GWK was increasingly away in response to scientific commitments, and Diddi and Irmi, who were extremely long-serving and skilled MTAs (medical-technical assistants). Very unusual compared with research technicians in most other countries they had undergone a detailed formal training, which was crowned by a specialist exam. Another place in the Department to acquire such "epigenetic conditioning" was the laboratory run by "Kömpchen" (Frau Waltraut Komp) who excelled as a master of neurohistology. Diddi, Irmi and Frau Komp had a strong influence on the sociology of the Kreutzberg Department, and it is not an exaggeration to say that they very effectively helped raise young researchers and that they took them under their wings (authors of this article included) (Fig. 1). Following official guidance by the MaxPlanck-Society at the time, MTAs were not eligible to coauthor research papers. However, we would always acknowledge their highly skilled contributions.

Few will argue that personnel matters are critical for any successful laboratory. There is no prototypical nerve cell as GWK once put it in a textbook chapter, and there is no prototypical scientist either it appears. Therefore, personnel management is a challenging subject in research labs, which often harbour eccentric characters that can accompany unique talents. The head of a laboratory has a great responsibility when selecting especially young researchers in order to create the right mix of personalities, talents and skills. In that sense, the 1980 s were undoubtedly fortunate, as so many highly cited research publications that have resulted from this era demonstrate. And as the authors of this publication can attest, this era and subsequent productive periods would have been far less likely and perhaps impossible in the absence of the very open atmosphere that characterised the Kreutzberg Department. While some could occasionally abuse the freedom and support we had, this happened very rarely overall and probably was a calculated risk, and none of us would have wanted to miss the open atmosphere that was so conducive to conversation and collaboration. "Science arises in conversations" as Heisenberg once put it and GWK clearly subscribed to this idea. Many successful doctoral students also attest to the success of this approach. 

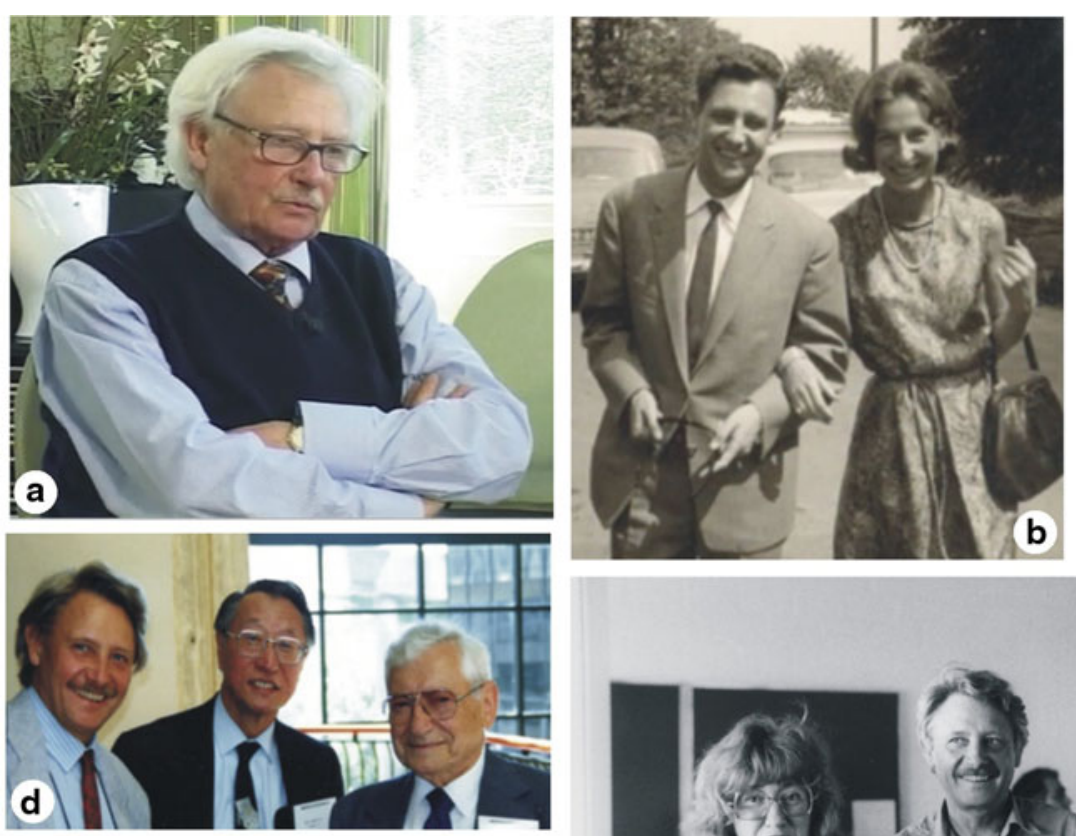

GWK 80

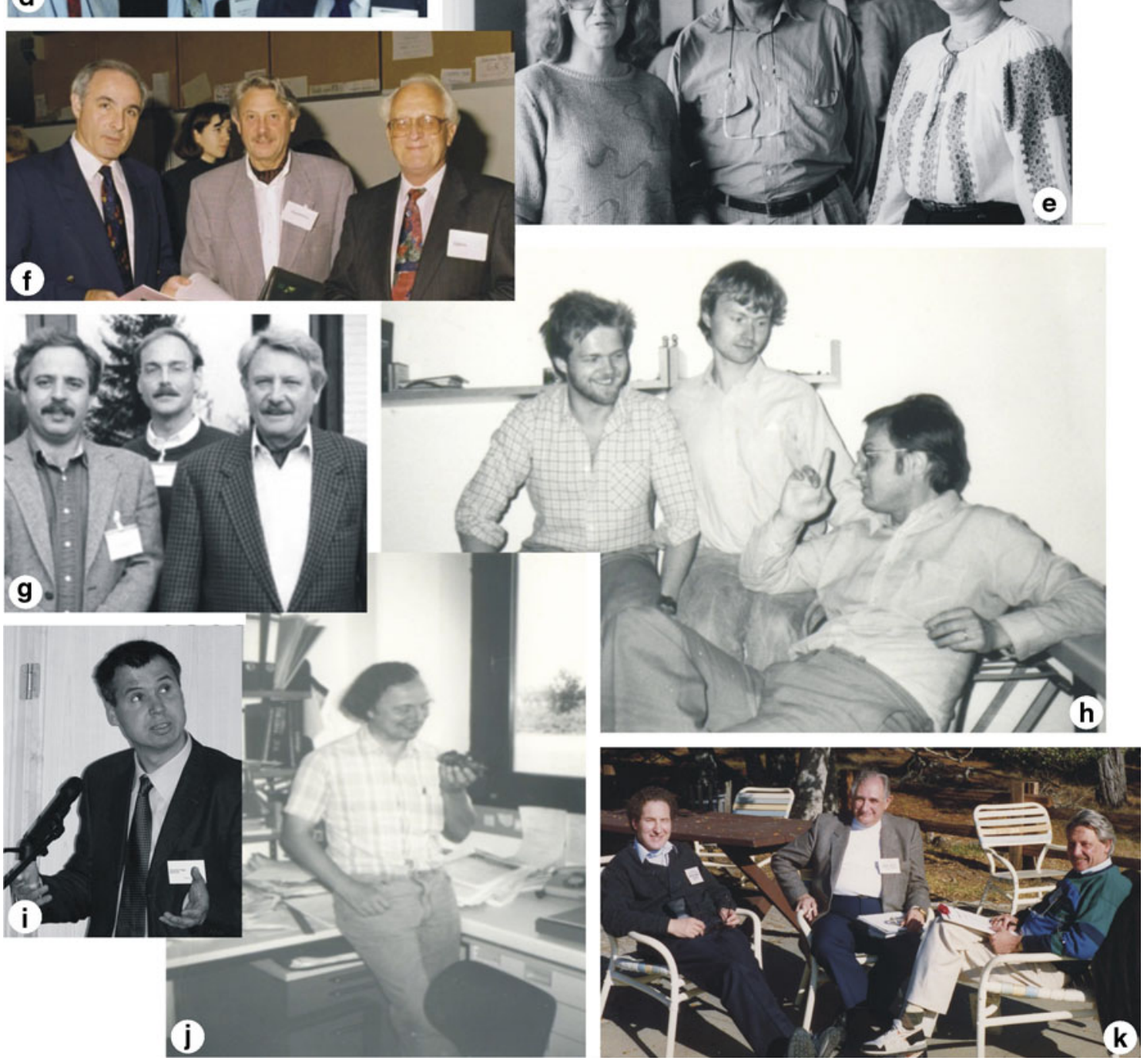


Fig. 1 a Professor Georg W. Kreutzberg in April 2008 during an interview conducted by Professor Rosemarie Grantyn, Berlin, taken from the movie, Georg Kreutzberg, a film produced by R. Grantyn and H. Kettenmann on behalf of Neurowissenschaftliche Gesellschaft e.V.; b Georg and Karin Kreutzberg, 1964; c GWK, 1966; d GWK, Asao Hirano and Harry Zimmerman, 1989, Dallas, Texas, USA; e Irmtraud Milojević ("Irmi"), GWK and Dietmute Büringer ("Diddi") during a departmental gathering in Martinsried, 1988; f Samuel Ludwin, GWK and Hume Adams (three presidents of the International Society of Neuropathology), 1993, Berlin, Germany; g Wolfgang J. Streit, Richard B. Banati and GWK, 1992, Titisee, Germany; h Manuel B. Graeber, Wolfram Tetzlaff and Lajos Toth, 1985, Martinsried, Germany; i Alexander Flügel, Martinsried, Germany, 2004; j Martin Reddington, 1985, Martinsried, Germany; k Geoffrey Raisman, the late Sergey Fedoroff, and GWK, 1989, Asilomar, CA, USA

\section{Scientific impact}

From 1979 to 1997, GWK served as a member of the Board of Directors at the Max-Planck-Institute of Psychiatry and Head of the Department of Neuromorphology. In 1984, he returned to the Massachusetts Institute of Technology, Cambridge, MA, USA, as a Visiting Scientist in the Department of Psychology and Brain Sciences headed by Professor Ann Graybiel. Another year as visiting scientist followed in 1993, this time at the Institute of Brain Research, University of Zurich, Zurich, Switzerland with Professor Martin Schwab. Georg Kreutzberg continued as a Member of the Board of Directors at the Max-PlanckInstitute of Neurobiology and Head of the Department of Neuromorphology, Martinsried from 1998 until he became Emeritus on 30 Sep 2000.

GWK received a large number of honours, too many to be listed here but a few should be mentioned. He was President of the German Cell Biology Society (1981-1985); Member of the Otto Loewi Center for Neurobiology, Hebrew University, Jerusalem, Israel, since 1986; recipient of the Rudolf F. Weiss Prize (1987); 1991-1998 Founder and Director of Programme, European Initiative for Communicators of Science (EICOS); recipient of the 1991 K.J. Zülch Prize; recipient of an honorary doctorate from the Albert Szent-Györgyi Medical University, Szeged, Hungary (1991); since 1991 Member of the Academia Scientiarum et Artium Europaea, Salzburg, Austria; recipient of the GSF Prize 1992; 1993-2001 Member of the Board of Trustees and President of the Research Council, International Research Paraplegia (IRP), Zurich, Switzerland; 1994-1997 President, International Society of Neuropathology; 1994-2000 Member, Governing Council of the International Brain Research Organization (IBRO); 1999-2000 President, German Neuroscience Society. He also served as a scientific referee for numerous organisations including the Nobelkommittén Karolinska Institutet, Stockholm, Sweden and was an editor or member of the editorial board of the following international journals: Acta Neuropathologica; Brain Pathology; Comments on Developmental Neurobiology; European Journal of Cell Biology; Glia; International Journal of Developmental Neuroscience; Journal of Cerebral Blood Flow and Metabolism; Journal für Hirnforschung; Journal of Molecular Medicine; Journal of Neurocytology; Journal of Neural Transmission; Journal of Neuroscience Research; Neurology Psychiatry and Brain Research; Neuropathology and Applied Neurobiology; Neuroscience; Perspectives on Developmental Neurobiology; and Restorative Neurology and Neuroscience.

Citations of published works represent a new and increasingly important measure of scientific impact and esteem. Georg Kreutzberg's h-index at age 80 is 80 , a very rare achievement in absolute terms and especially noteworthy because the total number of his publications is below 400 and his h-index is not largely based on coauthorships. As of July 2012, there were 54 articles that had earned 100 or more citations. The most highly cited articles (first or senior author positions only) are provided in the list of references: original research reports with 200 or more citations [3, 5, 7, 8, 19], 300 [6, 17], 400 [12, 16] and 500 [2], along with the three most highly cited review articles that have earned more than $700[1,18]$ and more than 2,000 citations [15], respectively. The latter publication, which stipulates microglia as a "sensor of pathology", is the most highly cited microglia article of all times. GWK's total number of citations without self-citations well exceeds 21,000 at the time of this writing.

Scientists need patience. Almost half a century has passed since the original description of "synaptic stripping" [2]. This paper was the first to indicate a role for microglia in synaptic plasticity based on ultrastructural data. Twenty years later, it was also in GWK's laboratory that the increased expression of CR3 complement receptors following axotomy was interpreted as evidence for a possible non-immunological involvement of the complement system in the CNS [6]. Both findings have generated more than 800 citations combined and others have recently independently provided support for the view that complement, synapses and microglia are crucially interlinked. In fact, maintenance of synapses in the CNS using their complement receptors may be the long sought normal function of microglial cells [4]. As a result, this "new" role of the microglia seems to be on its way to becoming one of the hottest topics in the neurosciences. Yet, two decades ago, the importance of these discoveries was already on the horizon for a selected few and due credit could not be given more appropriately than by the following quote. This historical text is an excerpt from "Castle", a piece of poetry written by Professor Geoffrey Raisman, London, after he attended the First International Symposium on Microglia, which took place in the autumn of 1993 at Castle Ringberg, 
Tegernsee, Germany: "The final session was held after dinner in a circular room in the height of the south tower, up the Landshuter Staircase, with shaped tables fitted like pie slices into a vast round. 35 armchairs shot a Russian roulette of wise thoughts into the centre of an empty circle. Then I began to see a life's work emerging, quiet and insistent. It was over quarter of a century since Nauta had introduced me at a meeting in Boston, to this quiet, unassuming man. Now the courtly, charming Nauta had been laid low by a stroke, and the single unexpected observation, that cut nerve cells lose their connections, had wound, like the silken thread Ariadne used to lead her lover from the Minotaur, to the understanding of this one cell, the microglial cell. So, as I listened to the fragments of the final discussion I could feel the hand, now loose, now gently guiding, the eye that had seen further."

Georg W. Kreutzberg is now an Emeritus Professor and Director at the Max-Planck-Institute of Neurobiology in Martinsried near Munich, Germany.

Acknowledgments We are indebted to Professor Anna Członkowska, $2^{\text {nd }}$ Department of Neurology, Institute of Psychiatry and Neurology, and Department of Pharmacology, Warsaw Medical University, Warsaw, Poland, for providing historical photographs.

\section{References}

1. Banati RB, Gehrmann J, Schubert P, Kreutzberg GW (1993) Cytotoxicity of microglia. Glia 7:111-118. doi:10.1002/glia. 440070117

2. Blinzinger K, Kreutzberg GW (1968) Displacement of synaptic terminals from regenerating motoneurons by microglial cells. Z Zellforsch Mikrosk Anat 85:145-157. doi:10.1007/bf00325030

3. Gehrmann J, Bonnekoh P, Miyazawa T, Hossmann KA, Kreutzberg GW (1992) Immunocytochemical study of an early microglial activation in ischemia. J Cereb Blood Flow Metab 12:257-269

4. Graeber MB (2010) Changing face of microglia. Science 330:783-788
5. Graeber MB, Kreutzberg GW (1986) Astrocytes increase in glial fibrillary acidic protein during retrograde changes of facial motor neurons. J Neurocytol 15:363-373

6. Graeber MB, Streit WJ, Kreutzberg GW (1988) Axotomy of the rat facial nerve leads to increased CR3 complement receptor expression by activated microglial cells. J Neurosci Res 21:18-24. doi:10.1002/jnr.490210104

7. Graeber MB, Tetzlaff W, Streit WJ, Kreutzberg GW (1988) Microglial cells but not astrocytes undergo mitosis following rat facial nerve axotomy. Neurosci Lett 85:317-321. doi: 10.1016/0304-3940(88)90585-x

8. Graeber MB, Streit WJ, Kreutzberg GW (1989) Identity of ED2positive perivascular cells in rat brain. $J$ Neurosci Res 22:103-106. doi:10.1002/jnr.490220114

9. Ikuta F (1996) Harry M Zimmerman MD (1901-1995). Neuropathology 16:157-158

10. Kreutzberg GW (1963) Changes of coenzyme (TPN) diaphorase and TPN-linked dehydrogenase during axonal reaction of the nerve cell. Nature 199:393-394

11. Kreutzberg GW (1966) Experimentelle Neuropathologie. Nervenarzt 37:437-439

12. Kreutzberg GW (1969) Neuronal dynamics and axonal flow. IV. Blockage of intra-axonal enzyme transport by colchicine. Proc Nat Acad Sci USA 62:722-728. doi:10.1073/pnas.62.3.722

13. Kreutzberg GW (1987) In memoriam Gerd Peters. Acta Neuropathol 74:207-208

14. Kreutzberg GW (1990) Walther Spielmeyer and Japanese Neuropathology. Brain Pathol 1:60-62

15. Kreutzberg GW (1996) Microglia: a sensor for pathological events in the CNS. Trends Neurosci 19:312-318. doi:10.1016/ 0166-2236(96)10049-7

16. Streit WJ, Kreutzberg GW (1987) Lectin binding by resting and reactive microglia. J Neurocytol 16:249-260. doi:10.1007/bf 01795308

17. Streit WJ, Kreutzberg GW (1988) Response of endogenous glial cells to motor neuron degeneration induced by toxic ricin. J Comp Neurol 268:248-263. doi:10.1002/cne.902680209

18. Streit WJ, Graeber MB, Kreutzberg GW (1988) Functional plasticity of microglia—a review. Glia 1:301-307. doi:10.1002/ glia.440010502

19. Streit WJ, Graeber MB, Kreutzberg GW (1989) Expression of Ia antigen on perivascular and microglial cells after sublethal and lethal motor neuron injury. Exp Neurol 105:115-126. doi:10.1016/ 0014-4886(89)90111-8 